\title{
Hydroacoustic Observation on the 2011 Tohoku Earthquake
}

\author{
Sukyoung Yun* and Won Sang Lee \\ Korea Polar Research Institute \\ 2011년 토호쿠 대지진의 수중음향 관측 \\ 윤숙영* - 이원상 \\ 극지연구소
}

\begin{abstract}
The $M_{W} 9.0$ thrust-fault earthquake has occurred in the Pacific coast of Tohoku, Japan, on March 11, 2011. We present the detection of the great earthquake and analyze $T$-waves associated with the main event and two other big aftershocks $\left(M_{W}>7\right)$ recorded in a hydroacoustic array $(\mathrm{H} 11 \mathrm{~N})$ in the Pacific Ocean by performing array and spectral analysis to examine characteristics of $T$-waves generated from the big events. The complex rupture process of the main event directly influences on the shape of the $T$-waves, and the peak locates on where $T$-waves excited from fast rupturing process arrive. We compare the two aftershocks with different fault type and show that the fault type and the source depth change shape and spectral contents of $T$-waves.
\end{abstract}

Keywords: the 2011 Tohoku Earthquake, Hydroacoustic monitoring, T-waves, IMS hydrophone array

요 약: 2011년 3월 11일에 일본 토호쿠 앞바다에서 규모 9.0의 대지진이 발생하였고 이는 전 세계 지진관측망뿐 아니 라 IMS(International Monitoring System)에서 운영하는 하와이 수중음향 관측망에도 기록되었다. 우리는 이 대지진을 비 롯한 두개의 규모 7 이상의 여진의 수중음향 자료에 대하여 방위각 및 스펙트럼 분석을 통해 복잡한 지진원에서 발생한 $T$ 파의 특성을 파악하고자 연구를 수행하였다. 이를 통해 복잡한 단층 파열 현상이 직접적으로 $T$ 파의 형태에 영향을 미 치는 것을 관측하였고, 빠른 단층 파열 과정에 의하여 발생한 $T$ 파가 중첩되는 구간에서 큰 에너지가 기록된 것을 확인 할 수 있었다. 두 여진에서 발생한 $T$ 파를 비교한 결과 단층 종류와 깊이에 의해 $T$ 파의 형태와 주파수 특성이 변하는 것을 확인하였다.

주요어: 2011 토호쿠 대지진, 수중음향관측, $T$ 파, IMS 수중음향 관측망

\section{Introduction}

The great 2011 Tohoku Earthquake $\left(M_{W} 9.0\right)$ has occurred offshore of the east coast of Honshu, Japan at 05:46 UTC on March 11, 2011. It is the fourth largest earthquake ever recorded since modern seismographs installed, and hundreds of aftershocks $(M>5)$ have been accompanied. This megathrust earthquake sequence started with an $M_{W} 7.3$ foreshock at 02:45 UTC on March 9, 2011, just to the north of the

2013년 10월 22일 접수; 2013년 11월 13일 수정; 2013년 11월 15일 채택 *Corresponding author

E-mail: yun@kopri.re.kr

Address: 213-3, Songdo-dong, Yeonsu-gu, Incheon 406-840

(C)2013, Korean Society of Earth and Exploration Geophysicists

This is an Open Access article distributed under the terms of the Creative Commons Attribution Non-Commercial License (http://creativecommons.org/ licenses/by-nc/3.0/) which permits unrestricted non-commercial use, distribution, and reproduction in any medium, provided the original work is properly cited. main-shock. According to the result of the moment-rate function of the main-shock, it peaked around $70 \mathrm{~s}$ from the origin time and continued about $150 \mathrm{~s}$ (Ammon et al., 2011; Ide et al., 2011; Wang and Mori, 2011). There are two aftershocks with magnitude bigger than $M_{W}$ 7.0. The biggest aftershock (A1 in Fig. 1, $M_{W}$ 7.9) occurred about $28 \mathrm{~min}$ later (06:15:41 UTC) near the southern end of the rupture, and an extensional faulting aftershock (A2 in Fig. 1, $M_{W}$ 7.7) followed after $10 \mathrm{~min}$ (06:25:51 UTC) in the Pacific plate (Fig. 1).

The International Monitoring System (IMS) is a worldwide network of observational technology that will help to verify compliance with and detect and confirm violations of the Comprehensive Nuclear Test-Ban Treaty (CTBT) (http:// www.state.gov). The IMS utilizes the four principal technologies: Seismological, radionuclide, hydroacoustic, and infrasound. There are 11 hydroacoustic stations operational over 
the world: five of them are $T$-phase stations installed on oceanic islands and the rest of them are equipped with hydrophones to detect ocean acoustic signals ( $T$-waves) from the underwater explosions such as underwater nuclear experiment, and they are maintained by Comprehensive NuclearTest-Ban Treaty Organization (CTBTO).

In general, $T$-waves are referred to seismically generated acoustic waves that are trapped and propagate within the SOund Fixing And Ranging (SOFAR) channel (Tolstoy and Ewing, 1950). The channeling efficiency of the SOFAR waveguide and low intrinsic attenuation in the water column allow us to detect long distance waterborne events as well as microseismic submarine earthquakes which had not been detected by land-based seismic networks. Taking advantage of the inheritance of hydroacoustics, we could apply the hydroacoustic method to examine submarine tectonic events in detail (e.g., Fox et al., 2001; Dziak et al., 2010). Even though hydroacoustics turns out to be a robust approach to investigate submarine earthquakes, it still has a difficulty in determining various source parameters precisely such as depths due to the complexity of $T$-phase excitation mechanism. It may lead us to collect more various well-defined seismic events via hydroacoustic observation, and then compile them systematically to develop a theoretical model to explain how $T$-waves are excited by different earthquake sources. In this sense, the 2011 Tohoku earthquake would be an excellent event to be looked into in terms of seismology as well as hydroacoustics since the quake was big enough to be captured by both seismic and hydroacoustic monitoring network around the world. In this study, we present the detection of the great earthquake and analyze $T$-waves associated with the main-shock of the quake and the two other big aftershocks recorded at a hydroacoustic array $(\mathrm{H} 11 \mathrm{~N})$ in the Pacific Ocean (Fig. 1) by performing array and spectral analysis to examine characteristics of $T$-waves generated from the big events.

\section{Data and Array Analysis}

The IMS hydrophone array consists of three hydrophones separated by $2 \mathrm{~km}$ away from each other (triangular configuration) (Fig. 1). Because all IMS data are available to member states of CTBT, we collect continuous data of the day that the events occurred from International Data Centre by requesting. Instrument response of the pressure sensors in $\mathrm{H} 11 \mathrm{~N}$ is nearly flat over a frequency band $10 \sim 100 \mathrm{~Hz}$ and

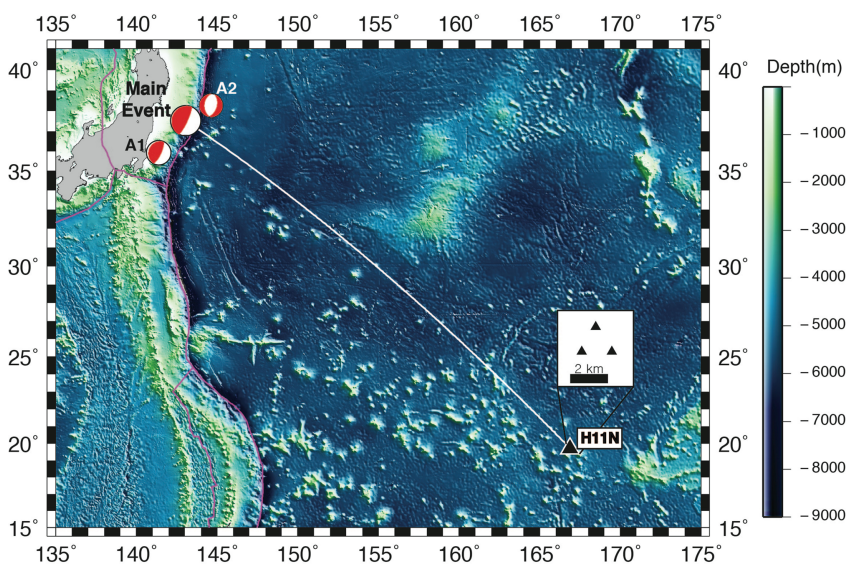

Fig. 1. Focal mechanisms of the main event (at 05:46:24 UTC on March 11, 2011) and two major $\left(M_{W}>7\right)$ aftershocks. A1 is a thrust faulting aftershock $\left(M_{W} 7.9\right)$ occurred at 06:15:41 UTC, and A2 is anormal faulting aftershock $\left(M_{W}\right.$ 7.7) at 06:25:51 UTC in the same day. The pink lines are boundaries of plates, and the black triangles represent IMS hydrophone triad in Hawaii. The white lines are the great circle paths between the main event and the stations.

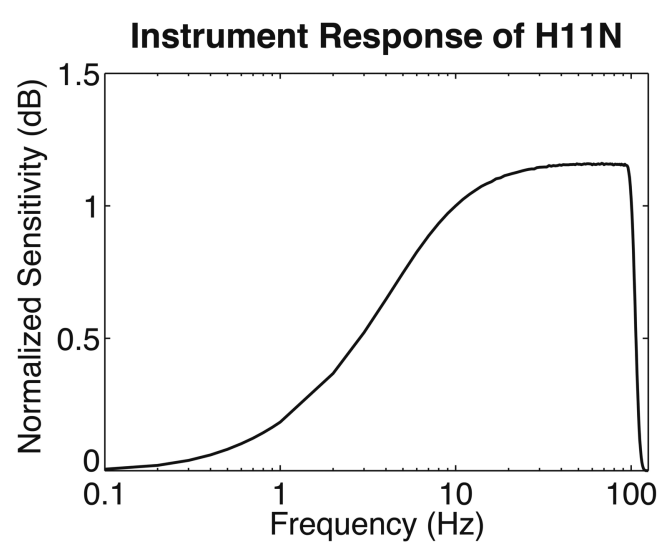

Fig. 2. Normalized instrumental response of the hydrophone sensors in IMS Hawaii station. Frequency response is nearly flat within the band of $10 \sim 100 \mathrm{~Hz}$ and falls off gradually below $10 \mathrm{~Hz}$.

decreases gradually below $10 \mathrm{~Hz}$ (Fig. 2). Each instrument has a 24-bit digitizer with a $250 \mathrm{~Hz}$ sampling rate.

We adopted the Progressive Multi-Channel Correlation (PMCC) method (Cansi, 1995), which has been successfully applied to analyze infrasound data, to conduct an azimuthal analysis on the IMS hydroacoustic data. The basic concept of this method is that we can determine the wave vectors, i.e., speed and azimuth, by calculating travel time differences using the cross-correlation method. The PMCC method enables us to determine the location of a number of submarine events using the IMS hydrophone triad (e.g., Graeber and Piserchia, 2004; Hanson and Bowman, 2005; Yun et al., 
2009), and in turn detailed information for the rupture propagation of the great Sumatra earthquake $\left(M_{W} 9.1\right)$ has been obtained (Guilbert et al., 2005; Tolstoy and Bohnenstiehl, 2006). We assume that wave front behaves as a plane wave in a far field. As signals recorded at all three hydrophones are originated from the same source, summation of time differences between all three pairs should be very close to zero, which is called the closure condition (Graeber and Piserchia, 2004). If the signals are coherent, all the three correlation coefficients should be close to 1 . In order to efficiently and reliably find $T$-wave signals, we impose criteria that are successfully used to locate submarine earthquakes in the Indian Ocean by Yun et al. (2009). For coherency between signals, product of the three coefficients must be larger than 0.064 , that is $c_{12} \times c_{23} \times c_{31} \geq(0.4)^{3}$, where $c_{i j}$ is the cross-correlation coefficient between waveforms of $i$-th and $j$-th sensors. For the closure condition, we require a condition of -0.016 $\leq \boldsymbol{t}_{12}+\boldsymbol{t}_{\mathbf{2 3}}+\boldsymbol{t}_{\mathbf{3 1}} \leq 0.016$, where $\boldsymbol{t}_{i j}$ is the travel time difference of signals between $i$-th and $j$-th sensors calculated from cross-correlation. A velocity criterion is that the speed component of a wave vector, $v_{T}$, has to be $1.45 \sim 1.5 \mathrm{~km} / \mathrm{s}$. We performed cross-correlation on the signals in a $2 \sim 20 \mathrm{~Hz}$ frequency band with a moving time window of 3.2 seconds. The standard deviation of the azimuthal error for the PMCC having this condition is $0.18^{\circ}$ (Yun et al., 2009).

\section{Results and Discussion}

In Fig. 3, we compared the rupture process of the great earthquake (Ide et al., 2011; left figure) with the result of azimuthal analysis from the PMCC method, time series of the hydroacoutic records at the three sensors in H11N, meansquare (MS) envelope, and the spectrogram (right figure). Ide et al. (2011) produced a spatio-temporal slip distribution map and calculated a moment-rate function by inverted broadband seismograms from 50 Global Seismographic Network stations. The colored stars and numbers denote the locations and time gaps after the rupture initiation for local maximum slips. Each slip is labeled as (a) (f) in chronological order. Because the propagation velocities of body waves in the crust are usually faster than the $T$-wave velocity $(\sim 1.45$ $\mathrm{km} / \mathrm{s}), T$-waves can arrive early when body waves propagate

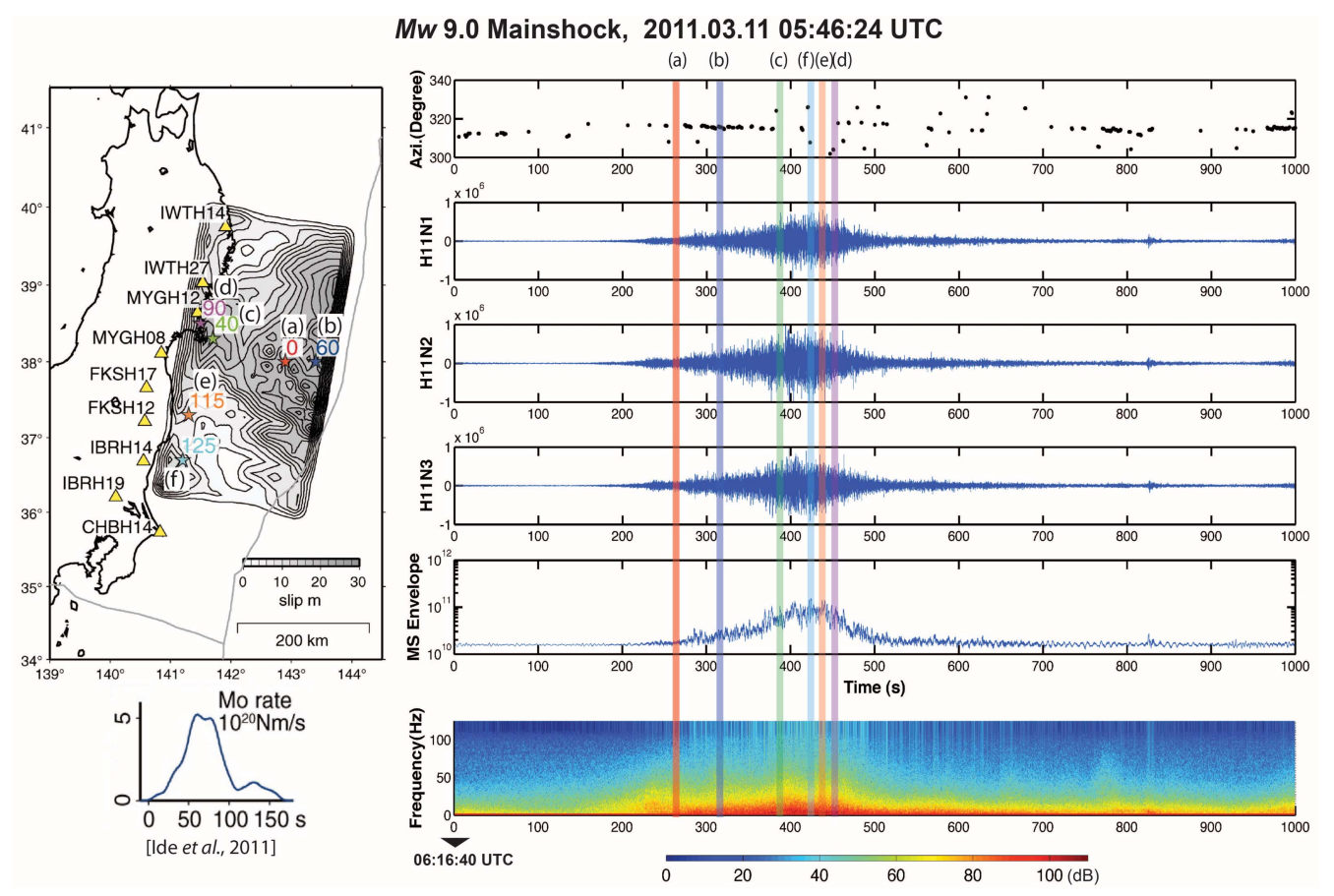

Fig. 3. (Left) Rupture process of the 2011 Tohoku earthquake from Ide et al., 2011. Reprinted with permission from AAAS. (Right) The azimuthal analysis results, time series of the hydroacoutic records at the three sensors in H11N, a MS envelope, and a spectrogram. The spatio-temporal slip distribution and moment rate function are calculated by inverted broadband seismograms at 50 Global Seismographic Network (GSN) stations (Ide et al., 2011). (a) (f), the locations and times after the rupture initiation of the local maximum slips are denoted by the colored stars and numbers, respectively. We calculated individual $T$-wave arrival times traveling from the locations of local maximum slips (stars) to $\mathrm{H} 11 \mathrm{~N}$ and marked them with solid lines corresponding to each event on the right panel. The MS envelope and spectrogram shows several local maxima, and many of those are coincide with the arrivals of the maximum slips, (a) (f). 
Table 1. Start times of the 6 local maximum slips (Ide et al., 2011) and arrival times of $T$-waves at $H 11 \mathrm{~N}$ from the slip. (a) $\sim$ (f) are labels of the local maximum slips in chronological order. Arrival times are calculated by adding travel times to the star times. The last low is time lags from the start time of the plots in Fig. 3.

\begin{tabular}{lcccccc}
\hline \hline & (a) & (b) & (c) & (d) & (e) & (f) \\
\hline $\begin{array}{l}\text { Times after the } \\
\text { rupture initiation (s) }\end{array}$ & 0 & 40 & 60 & 90 & 115 & 125 \\
$\begin{array}{l}\text { Arrival times after } \\
\text { the rupture initiation(s) }\end{array}$ & 2085 & 2211 & 2129 & 2280 & 2261 & 2253 \\
Time lags from 6:16:40 UTC & 269 & 395 & 313 & 464 & 445 & 437 \\
\hline
\end{tabular}

long distance in the crust and then are converted into $T$ waves lately. However, their amplitudes are usually low because of high attenuation in the crust. In other word, the biggest energy can be excited on around epicenter where the crustal path is shortest. Accordingly, we calculated individual $T$-wave arrival times traveling from the epicenters of local maximum slips (stars) to H11N (Table 1) and marked them with solid lines corresponding to each event on the right panels of Fig. 3. T-wave velocity in this region is determined as $1.465 \mathrm{~km} / \mathrm{s}$, which is calculated from $T$-wave arrivals of a $M_{b} 5.5$ aftershock occurred at 06:18:45 UTC on 12 March, 2011. T-waves associated with the aftershock have a clear and unique peak, which allow us to calculate $T$-wave velocity.

As we assume that it is an impulsive point source, and the crust is homogeneous, $T$-wave envelope becomes symmetric and has a unique peak. However, a complex rupture process and excitation mechanism (e.g., the Tohoku earthquake) makes the shape of envelope irregular- and complex-pattern. In Fig. 3, the MS envelope and spectrogram show several local maxima, and many of those coincide with the arrivals of maximum slips, (a) (f). However, the amplitude of the envelope is not well correlated with the source time function that biggest energy is released around $60 \mathrm{~s}$. The blue line, (b), represents slip at $60 \mathrm{~s}$ when the biggest moment radiated, but the maximum $T$-wave energy arrives at the later part of the wave train. The phenomenon could be explained by two reasons: 1) In spite of one spot is localized as a center of the biggest slip, the slips occur across the whole fault plane at $60 \mathrm{~s}$ from the rupture initiation, and the length of the slip region along the azimuthal direction to the station is about $200 \mathrm{~km}$ (Ide et al., 2011; Lay et al., 2011). Thus, although seismic energy releases at the same time along the fault plane, the arrival of $T$-waves could be delayed even over $100 \mathrm{~s}$ in this case. In addition, the several local maximum slips, (c), (f), (e), and (d), arrive within $50 \mathrm{~s}$ time window, which might cause enhancement of the amplitude of $T$ wave energy due to superposition of coherent waves. The results of azimuthal analysis also support this hypothesis. The black dots in the azimuth plot are almost linear until the event (c) arrives, then they start to be scattered or when the events (c), (f), (e), and (d) arrive. Superposed signals from various locations may hamper to find incoming wave direc-
A1) Mw 7.9 Aftershock, 2011.03.11 06:15:41 UTC
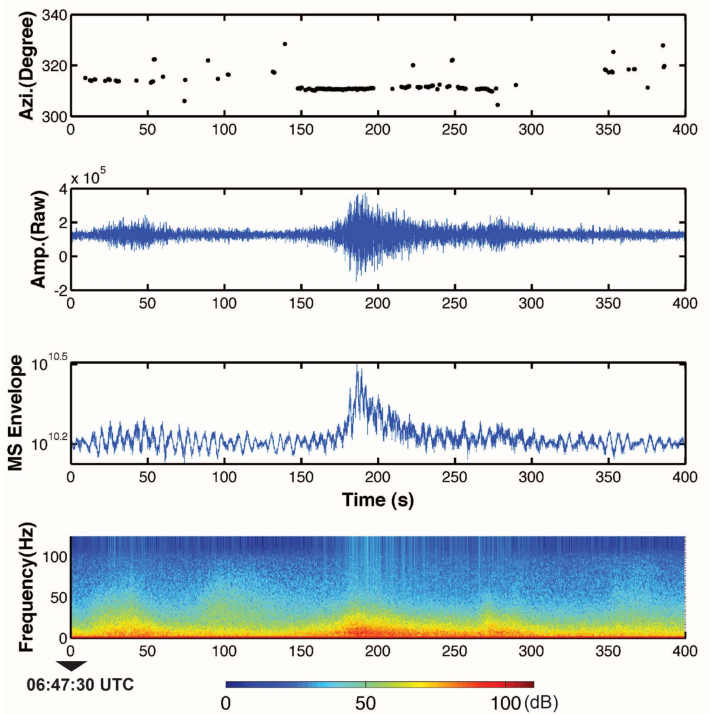

A2) $M w$ 7.6 Aftershock, 2011.03.11 06:25:51 UTC
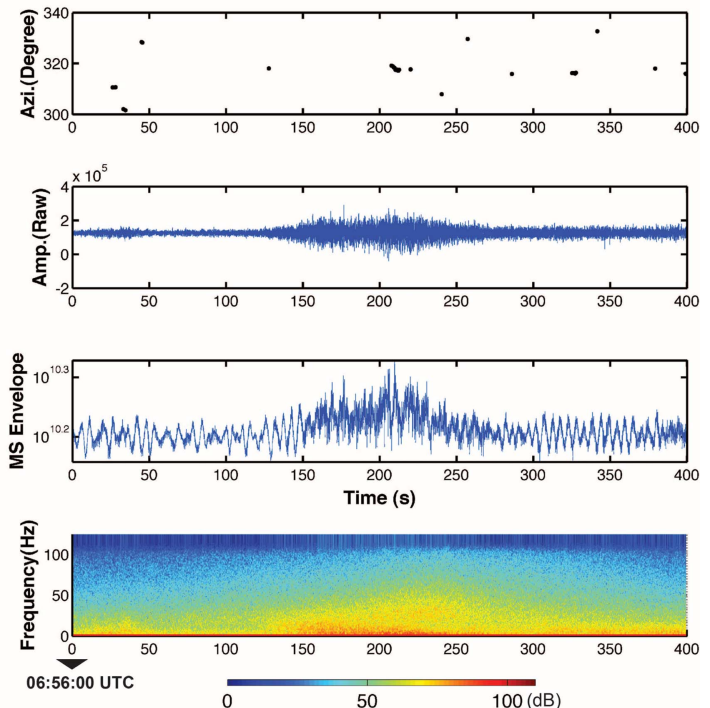

Fig. 4. Plots of azimuths, time series of the hydoroacoutic records at the H11N, MS envelopes, and spectrograms for A1, the thrust faulting aftershock $\left(M_{\mathrm{W}} 7.9\right)$ and $\mathrm{A} 2$, the normal faulting aftershock $\left(M_{\mathrm{W}} 7.7\right)$. The differences in the source depth and excitation mechanism cause different shapes and frequency contents of $T$-waves. 
tions by means of the cross-correlation method. 2) Another reason for weak amplitude of the earlier part of the $T$-waves could be caused by slow rupture velocity. The previous rupture model studies for the Tohoku earthquake (e.g., Ammon et al., 2011; Lay et al., 2011; Wang and Mori, 2011) report that the rupture speed kept staying very slow with $1.0 \sim 1.5$ $\mathrm{km} / \mathrm{s}$ until first $80 \mathrm{~s}$, and finally it speeds up to $2.5 \sim 3 \mathrm{~km} /$ $\mathrm{s}$ as the rupture expands southwestward. The low-velocity rupture is a typical characteristic of tsunamigenic earthquakes, and the Tohoku earthquake radiated most of seismic energy while the slow rupture process was continuing during $60 \sim$ $80 \mathrm{~s}$ from the origin time. The slow rupturing would make big tsunami efficiently but is hard to generate strong $T$-waves because $T$-wave amplitude is likely to be controlled by high frequency components (Okal et al., 2003).

In Fig. 4, we present plots of azimuths, time series of the hydroacoustic records at the H11N, MS envelope, and spectrogram for the $\mathrm{A} 1$, the thrust faulting aftershock $\left(M_{W} 7.9\right)$ and $\mathrm{A} 2$, the normal faulting aftershock $\left(M_{W} 7.7\right)$. We found that $T$-wave envelopes vary as earthquake focal mechanism changes. T-wave envelope of the A1 event (left figure) has sharp peaks and shows deficient of high frequency energy. However, the $T$-wave envelope generated by normal faulting (right figure) hasa spindle shape envelope and contains abundant high frequency energy even though its magnitude is smaller than that of A1. The source depths of A1 and A2 defined by land-based seismic data are $42 \mathrm{~km}$ and $18 \mathrm{~km}$, respectively (http://earthquake.usgs.gov). In general, the medium heterogeneity in the ocean crust is quite strong so that high frequency energy content rapidly attenuates during propagation. It tells us that high frequency content of seismic energy for deep focus events is difficult to remain at hydroacoustic data. These features imply that the different $T$-wave excitation mechanisms and source depths would affect the shape and frequency contents of $T$-waves.

When source and excitation mechanisms of two events are similar, deeper earthquakes are usually characterized by longer duration and gentler rising slope (Yang and Forsyth, 2003). However, the results shown in this study are somewhat inconsistent with the previous ones; the $T$-wave envelope of the deeper source (A1) has a steeper rise. For the case of thrust fault, $T$-wave excitation mechanism is totally different from that of normal fault events. In the subduction system, seismic energy can be trapped within the fault low-velocity zone along the subducting plate. Then, the trapped seismic waves are converted into the water column and propagate as
$T$-waves. Therefore, it seems that the subduction system plays a focusing role of acoustic conversions on narrow regions so that this could result in sharp peaks and short duration of $T$ waves.

\section{Conclusion}

In this study, we present the detection of the great Tohoku earthquake and analyze $T$-waves associated with the mainshock and the two big aftershocks recorded at an IMS hydroacoustic array by performing array and spectral analysis. The complex rupture process of the main event directly influences on the shape of the $T$-waves. We observed that there is discrepancy between the moment rate function and the envelope function of $T$-wave due to the fast rupturing from $80 \mathrm{~s}$ in lapse time and superposing $T$-wave energies from other rupture processes. The superposed waves from various source points on the fault plane cause a scattered pattern in the result of azimuthal analysis. Comparing $T$-waves from the two aftershocks having different focal mechanisms, we find out that source mechanism and focal depth affect frequency contents and the envelope shapes of the $T$-waves.

\section{Acknowledgements}

The authors would like to thank editor and two anonymous reviewers for their comments that helped us to improve the manuscript. This research is supported by KOPRI research grants PN13050 (CATER 2012-8080) and PE13050.

\section{References}

Ammon, C. J., Lay, T., Kanamori, H., and Cleveland, M., 2011, A rupture model of the 2011 off the Pacific coast of Tohoku Earthquake, Earth Planets Space, 63, 693-696.

Cansi, Y., 1995, An automatic seismic event processing for detection and location: the PMCC method, Geophys. Res. Lett., 22, 1021-1024.

Dziak, R. P., Park, M., Lee, W. S., Matsumoto, H., Bohnenstiehl, D. R., and Haxel, J. H., 2010, Tectonomagmatic activity and ice dynamics in the Bransfield Strait back-arc basin, Antarctica, J. Geophys. Res., 115, B01102, doi:10.1029/2009JB006295.

Fox, C. G., Matsumoto, H., and Lau, T. A., 2001, Monitoring Pacific Ocean seismicity from an autonomous hydrophone array, J. Geophys. Res., 106, 4183-4206.

Graeber, F. M., and Piserchia, P. F., 2004, Zone of T-wave excitation in the NE Indian Ocean mapped using variations in back azimuth over time obtained from multi-channel correlation of IMS hydrophone triplet data, Geophys. J. Int., 
158, 239-256.

Guilbert, J., Vergoz, J., Schisselé, E., Roueff, A., and Cansi, Y., 2005 , Use of hydroacoustic and seismic arrays to observe rupture propagation and source extent of the $M_{\mathrm{W}}=9.0$ Sumatra earthquake, Geophys. Res. Lett., 32, L15310, doi:10.1029/ 2005GL022966.

Hanson, J. A., and Bowman, J. R., 2005, Indian Ocean ridge seismicity observed with a permanent hydroacoustic network, Geophys. Res. Lett., 32, L06301,doi:10.1029/2004GL021931.

Ide, S., Baltay, A., and Beroza, G. C., 2011, Shallow Dynamic Overshoot and Energetic Deep Rupture in the $2011 M_{\mathrm{W}} 9.0$ Tohoku-Oki Earthquake, Science, 332, 1426-1429.

Lay, T., Ammon, C. J., Kanamori, H., Xue, L., and Kim, M. J., 2011, Possible large near-trench slip during the $2011 \mathrm{Mw} 9.0$ off the Pacific coast of Tohoku Earthquake, Earth Planets Space, 63, 687-692.

Okal, E. A., Alasset, P.-J., Hyvernaud, O., and Schindelé, F., 2003, The deficient $\mathrm{T}$ waves of tsunami earthquakes, Geophys. J. Int., 152, 416-432.
Tolstoy, I., and Ewing, M., 1950, The T-phase of the shallowfocus earthquake, Bull. seism. Soc. Am., 40, 25-51.

Tolstoy, M., and Bohnenstiehl, D. R., 2006, Hydroacoustic contributions to understanding the December 26th 2004 great Sumatra-Andaman Earthquake, Surv. Geophys., 27(6), 633646.

Wang, D., and Mori J., 2011, Rupture process of the 2011 off the Pacific coast of Tohoku Earthquake $\left(M_{\mathrm{W}} 9.0\right)$ as imaged with back-projection of teleseismic $P$-waves, Earth Planets Space, 63, 603-607.

Yang, Y., and Forsyth, D. W., 2003, Improving epicentral and magnitude estimation of earthquakes from $\mathrm{T}$ phases by considering the excitation function, Bull. seism. Soc. Am., 93, 2106-2122.

Yun, S., Ni, S., Park, M., and Lee, W. S., 2009, Southeast Indian Ocean-Ridge earthquake sequences from cross-correlation analysis of hydroacoustic data. Geophys. J. Int., 179, 401407. 